\title{
A Pattern of Glomerular Diseases in Egyptian Children: A Single-center Experience
}

\author{
Hoda Atef Abdelsattar Ibrahim ${ }^{1 *}$ (D) Aya Amin ${ }^{2}$ D, Ahmed Zeid $^{1}$ (D) Samar Sabry ${ }^{1}$, Hesham Safouh $^{1}$ (iD \\ ${ }^{1}$ Department of Pediatrics, Faculty of Medicine, Cairo University, Giza, Egypt; ${ }^{2}$ Department of Biostatistics and Cancer \\ Epidemiology, National Cancer Institute, Cairo University, Giza, Egypt
}

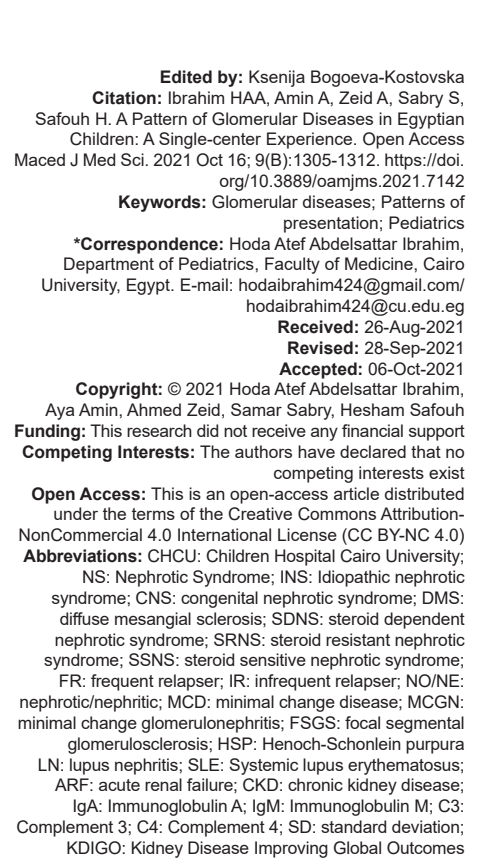

\section{ABSTRACT}

BACKGROUND: Findings indicative of the glomerular disease are proteinuria, hematuria, nephrotic syndrome (NS), hypertension, and renal insufficiency. These presentations can be used to define different clinical patterns that resemble different underlying etiologies.

METHODS: This study is a cross-sectional study enrolled in Children Hospital Cairo University. The study participants were recruited on two stages, retrospective and prospective stages. In the retrospective stage, all eligible patients across 5 years (between 2011 and 2015) with any glomerular disease were included in the study. In addition, prospectively, the new cases a long 6 months (from February 2016 till July 2016) with glomerular diseases were included in the study.

RESULTS: A total of 594 cases with different glomerular diseases were identified. Cases were two groups: The retrospective group that involved 543 cases and the prospective group that included 51 cases. In the retrospective part of the study, the most common presentations were NS $(68 \%)$, nephritis $(16.4 \%)$, gross hematuria $(10.5 \%)$ and nephrotic/nephritic syndrome (3.5\%). The most common biopsies in the retrospective study were NS: MCNS (27.3\%), NS: focal segmental glomerulosclerosis (FSGS) (23.4\%), NS: Mesangioproliferative GN (9.4\%), NS: Membranous GN $(2.3 \%)$, Crescentric GN (3.9\%), Membranous GN $(0.8 \%)$, MPGN $(0.8 \%)$, congenital nephrotic syndrome (CNS):Diffuse Mesangial Sclerosis (3.9\%), CNS: Finnish type (2.3\%), Alport (4.7\%), IgA nephropathy $(3.9 \%)$, IgM nephropathy (1.6\%), lupus nephritis (LN) (3.1\%), Thin basement membrane disease (3.1\%), and others $(9.4 \%)$ In the prospective study, the most common presentations were NS $(76.5 \%)$, nephritis $(11.8 \%)$, nephrotic/ nephritic syndrome $(7.8 \%)$, and gross hematuria (3.9\%). The biopsies results were mainly NS: FSGS (33.3\%) and NS: MCNS (33.3\%). Other biopsies results in the prospective part were NS: Mesangioproliferative GN (16.7\%), LN (8.3\%), and IgA nephropathy $(8.3 \%)$

CONCLUSION: The most common glomerular disease in childhood is NS. The most common pathology of glomerular diseases is minimal change NS.

\section{Introduction}

There are primary and secondary disorders that can lead to glomerular diseases [1]. The variations regarding the pattern of renal diseases among the pediatrics are possibly related to differences in environmental risk factors for renal diseases, genetic predisposition, and the clinical and laboratory capacities in the diagnosis [2].

Glomerular injury can produce impairment of the selective filtering properties of the kidney and subsequent reduction in the glomerular filtration rate (GFR) [3]. The severity and nature of the defect (i.e., underlying disease and pathologic lesion) determine the extent of hematuria, proteinuria, WBCs casts in the urine, and the level of the functional impairment. These variables further determine the clinical presentation [4]. Investigations may include kidney function tests, urine analysis, imaging, and renal biopsy [5]. Renal biopsy can help in determining the specific diagnosis, evaluating the level of disease severity and activity, and so can be a guide to proper therapeutic interventions and aids in predicting the prognosis. There has been an overall global change regarding the pattern of glomerular diseases across the past five decades [6]. This study aimed at identifying the different patterns of presentation of glomerular diseases as well as recognizing the pathology underlying these diseases.

\section{Methods}

This study is cross-sectional (retrospective and prospective). Consecutive sampling was used to recruit the study participants. The present study is a cross-sectional 
one performed at $\mathrm{CUCH}$. The study included two stages; retrospective and prospective stages. To the best of our knowledge, retrospective data and information are known to have some disadvantages. For example, the large number of different clinical observers could present variations and inconsistencies in clinical observations. The retrospective nature of this study limited the amount of data that could be collected. As a trial to make our results more accurate and decrease the bias from these drawbacks from any retrospective study, we incorporated another prospective study. This explains the reason for the study group subdivision into retrospective and prospective ones. In the retrospective stage: A consecutive sample of all eligible patients presenting with glomerular diseases over a 5-year period (2011-2015) was enrolled, the required data were taken through revising the medical achieves and records. In the prospective part of the study, all eligible cases who presented with a provisional diagnosis of any glomerular disease in a 6 months period were enrolled in the study using a consecutive sampling method. Data collection in this part of the study was performed by enrolling the history, clinical examination, and investigations. Children with the age of the onset of disease below 12 years, who were presenting with any glomerular disease, that is, definitions indicative of glomerular diseases are proteinuria, hematuria (that might be microscopic or macroscopic), nephrotic syndrome (NS), hypertension, and renal impairment and whose parents or caregivers agreed to be enrolled in the study were matching with the inclusion criteria. Children with cause of hematuria or renal impairment that was proved to be of non-glomerular origin (e.g., of these criteria are those who had hematuria due to stones or urinary tract infections or those who had renal impairment due to congenital anomalies) and those with insufficient data were matching with the exclusion criteria.

\section{Diagnostic criteria to classify different types of the glomerular diseases include}

1. Proteinuria: Proteinuria is present when the levels of urinary protein excretion are higher than $100-150 \mathrm{mg} / \mathrm{m}^{2} /$ day in children. Nephrotic range proteinuria in children is defined as protein excretion of $>40 \mathrm{mg} / \mathrm{m}^{2} / \mathrm{h}$

2. Hematuria: hematuria is present when $\geq 5$ red blood cells per high-power field in 3 of 3 consecutive centrifuged specimens taken at least 1 week apart. Hematuria can be either gross (macro hematuria, i.e., overtly bloody, smoky, or tea-colored urine) or microscopic. It may also be symptomatic or asymptomatic, transient or persistent, and isolated or associated with proteinuria and other urinary abnormalities. Persistent microscopic hematuria can be associated with bouts of macro hematuria (recurrent gross hematuria)

3. Arterial hypertension is present when the average blood pressure at or above $95^{\text {th }}$ percentile for the age, sex, height, when measured multiple times over three visits or more

4. Renal insufficiency: See later: Criteria of acute kidney injury (AKI) and chronic kidney disease (CKD).

\section{Study sample size}

A total of 594 cases with different glomerular diseases were involved in the study. Cases were two groups: The retrospective group that included 543 cases and the prospective group that involved 51 patients.

\section{Ethical considerations}

IRB approval and Consent: The study protocol and the consents were revised and approved by the IRB of Cairo University Hospitals (IRB Approval Number: I-360414).

Privacy and confidentiality: Throughout the study, the privacy and confidentiality of the data were perceived; the results were presented anonymously without disclosure of patients' personal identifying information.

\section{Data}

For each patient; the following were obtained:

1. Demographic data: Age at presentation and sex

2. Clinical data:

Presenting manifestations were categorized into:

- NS: Patients who were presenting with generalized edema (characteristic of nephrotic patients, i.e., starting periorbital) and nephrotic range proteinuria, with or without oliguria. The age subdivided those patients into congenital NS (0-0.3 years), infantile NS (0.4-1 year), and childhood NS (above one year)

- Nephritis: Patients who were presenting with hematuria, proteinuria (non-nephrotic range proteinuria: $<40 \mathrm{mg} / \mathrm{m}^{2} / \mathrm{h}$ ) with or without oliguria, and hypertension. Patients who developed acute renal failure, their presentations are categorized in (Acute renal failure $[A R F]$ ) group

- Nephrotic - nephritic syndrome (NO/ $\mathrm{NE}$ ): Patients with mixed features of the mentioned above

- $\quad$ ARF with impaired kidney functions (Azotemia).

Definition of AKI (as mentioned in KDIGO $A K I)$ : Consists of either increase in serum creatinine by $\geq 0.3 \mathrm{mg} / \mathrm{dL}$ from baseline ( $\geq 26.5 \mathrm{mcmol} / \mathrm{L}$ ) within $48 \mathrm{~h}$ or an increase in serum creatinine to $\geq 1.5$ times 
baseline within the preceding 7 days or urine volume $\leq 0.5 \mathrm{~mL} / \mathrm{kg} / \mathrm{h}$ for $6 \mathrm{~h}$ [7]

- Recurrent gross hematuria: Bouts of macro hematuria, which are possible to be associated with microhematuria (microscopic hematuria) that could be persistent between the attacks of these bouts

- Microscopic hematuria: Which could be accidentally discovered in our study or as a part of the original disease

- $\quad$ Accidentally discovered proteinuria.

- The CKD: CKD is present when kidney damage, either functional or structural, occurs or by a deterioration in the GFR below $60 \mathrm{~mL} / \mathrm{min} / 1.73 \mathrm{~m}^{2}$ of body surface area for $>3$ months.

Stage 1: Kidney damage with normal or increased GFR ( $\geq 90)$

Stage 2: Kidney damage with mild decreased GFR (60-89)

Stage 3: Moderate decreased GFR (30-59)

Stage 4: Severe decreased GFR (15-29)

Stage 5: Kidney failure, GFR is less than $(<15)$ [8], [9]

- The definitive diagnosis such as Alport syndrome, congenital NS Finnish type, congenital NS Diffuse Mesangial Sclerosis (DMS), Henoch-Schonlein Purpura, IgA nephropathy, IgMnephropathy, lupus nephritis (LN), Post-Streptococcal Glomerulonephritis (PSGN), Steroids Dependent NS (SDNS), SDNS turns into Frequent relapser (FR), SDNS turns into infrequent relapser (IR), Steroids Resistant NS (SRNS), SRNS turns into IR, Steroids Sensitive NS (SSNS), and Thin basement membrane disease.

\section{NB}

1. SSNS: Patients who respond to daily steroid therapy within 4 weeks

2. SDNS: Patients who relapse during withdrawal or within 14 days after tapering steroids

3. IR: Patients who have less than six relapses per year or less than three relapses per 6-month period

4. FR: Patients who have more than six relapses per year or more than three relapses per 6-month period

5. SRNS: Failure to achieve remission after 6 weeks of steroid treatment.

The provisional diagnosis: based on the presenting features, such as NS, recurrent gross hematuria, and acute nephritis.

- The results of the renal biopsies performed: such as MCNS, FSGS,
Membranoproliferative glomerulonephritis (GN), mesangioproliferative GN, Membranous GN, Crescentric GN, Congenital NS: DMS, Congenital NS: Finnish type, Alport, IgA nephropathy, IgM nephropathy, LN, Thin basement membrane disease, and Thrombotic microangiopathy. NB: Criteria for performing renal biopsies in glomerular diseases, for example, Nephritic syndrome:

1. NS (nephrotic range proteinuria)

2. Normal complement

3. Hematuria, proteinuria, hypocomplementemia, and impaired kidney function for more than 3 months after the onset

4. Rapidly progressive GN or persistent renal dysfunction more than 2 weeks.

NS:

1. SRNS: Failure to achieve remission after 6 weeks of steroid treatment

2. When the diagnosis of MCNS is unlikely.

- $\quad$ The patients age is less than one year or more than 11 year

- $\quad$ Presence of gross hematuria

- $\quad$ Presence of marked hypertension

- $\quad$ Presence of hypocomplementemia

- Renal impairment.

3. Rapidly progressive GN (crescentic GN)

4. Systemic disease with renal involvement to assess severity, for example, Systemic lupus erythematosus (SLE)

5. Chronic renal failure of uncertain etiology

6. Persistent glomerular hematuria

7. Persistent non-orthostatic proteinuria

8. Acute renal failure: If associated with nephrotic/ nephritic syndrome, vasculitis, or evidence of systemic disease.

\section{Statistical analysis}

Data were subjected to computer-assisted statistical analysis using a statistical package for social science "SPSS" VERSION 24. Nominal data were expressed as frequency and percentages. Numerical data were expressed as mean \pm standard deviation.

\section{Results}

\section{Retrospective part of the study}

In the retrospective part, the study included 543 children who were following up in pediatric nephrology clinic at Children Hospital Cairo University (CHCU) in a period of 5 years (2011-2015) with provisional diagnoses of glomerular diseases. 
The demographic characteristics of the patients showed that the mean age was $5.2 \pm 2.9$ years, male to female ratio was 1.7:1 (Table 1).

Table 1: Age and gender distribution of the study participants

\begin{tabular}{llll}
\hline Retrospective study $n=543$ & & & \\
\hline Age & Male & Female & Total \\
\hline Mean age $\pm \mathrm{SD}^{*}$ (years) & $5.4 \pm 2.8$ & $5.0 \pm 2.9$ & $5.2 \pm 2.9$ \\
Range (years) & $(0.1-11)$ & $(0.1-11)$ & $(0.1-11)$ \\
\hline Prospective study $n=51$ & Male & Female & Total \\
\hline Age & $4.5 \pm 2.6$ & $4.4 \pm 2.8$ & $4.5 \pm 2.7$ \\
\hline Mean age $\pm \mathrm{SD}^{*}$ (years) & $(0.5-10.5)$ & $(0.2-11)$ & $(0.2-11)$ \\
Range (years) & & &
\end{tabular}

The clinical manifestations of the patients showed that the majority of patients $(68 \%)$ were presented with NS. $19.3 \%$ of the patients showed complete resolution, while $77 \%$ of them had stage 1 CKD at the end of follow-up (Table 2).

Table 2: Clinical manifestations of the study participants at presentation

\begin{tabular}{|c|c|c|}
\hline Clinical manifestations & Retrospective part $(n=543)$ & Percent \\
\hline Pattern of presentation & Frequency & \\
\hline NS & 369 & 68.0 \\
\hline Nephritis & 89 & 16.4 \\
\hline Gross hematuria & 57 & 10.5 \\
\hline $\mathrm{NO} / \mathrm{NE}$ & 19 & 3.5 \\
\hline Microscopic hematuria & 4 & 0.7 \\
\hline ARF & 3 & 0.6 \\
\hline Asymptomatic persistent proteinuria & 1 & 0.2 \\
\hline Accidently discovered proteinuria & 1 & 0.2 \\
\hline Hypertension & Frequency & Percent \\
\hline No and/or missed & 45 & 88.2 \\
\hline Yes & 6 & 11.8 \\
\hline Follow up & Mean & $\mathrm{SD}^{*}$ \\
\hline Follow up duration (years) & 1.7 & 1.3 \\
\hline Resolution & Frequency & Percent \\
\hline Yes & 105 & 19.3 \\
\hline No & 438 & 80.7 \\
\hline CKD at end of follow-up & Frequency & Percent \\
\hline No & 105 & 19.3 \\
\hline Stage 1 & 418 & 77.0 \\
\hline Stage 2 & 10 & 1.8 \\
\hline Stage 3 & 2 & 0.4 \\
\hline Stage 4 & 3 & 0.6 \\
\hline Stage 5 & 5 & 0.9 \\
\hline \multicolumn{3}{|c|}{ Prospective part $(n=51)$} \\
\hline Pattern of presentation & Frequency & Percent \\
\hline NS & 39 & 76.5 \\
\hline Nephritis & 6 & 11.8 \\
\hline $\mathrm{NO} / \mathrm{NE}$ & 4 & 7.8 \\
\hline Gross hematuria & 2 & 3.9 \\
\hline Hypertension & Frequency & Percent \\
\hline Yes & 6 & 11.8 \\
\hline No & 45 & 88.2 \\
\hline Follow-up & Mean & $\mathrm{SD}^{*}$ \\
\hline Follow-up duration (years) & 0.38 & 0.17 \\
\hline CKD at end of follow up & Frequency & Percent \\
\hline Resolution & 6 & 11.8 \\
\hline Stage 1 & 45 & 88.2 \\
\hline
\end{tabular}

Table 3: The provisional diagnoses of the cases

\begin{tabular}{|c|c|c|}
\hline \multirow[t]{2}{*}{ Provisional diagnosis } & Retrospective study $(n=543)$ & \multirow[t]{2}{*}{ Percent } \\
\hline & Frequency & \\
\hline Congenital (NS) nephrotic syndrome & 18 & 3.3 \\
\hline Infantile (NS) nephrotic syndrome & 10 & 1.8 \\
\hline Childhood NS (nephrotic syndrome) & 361 & 66.5 \\
\hline Acute nephritis & 125 & 23.0 \\
\hline Recurrent gross hematuria & 22 & 4.1 \\
\hline ARF (acute renal failure) & 6 & 1.1 \\
\hline Not yet diagnosed & 1 & 0.2 \\
\hline Total & 543 & 100.0 \\
\hline \multirow[t]{2}{*}{ Provisional diagnosis } & Prospective study $(n=51)$ & \multirow[t]{2}{*}{ Percent } \\
\hline & Frequency & \\
\hline Congenital NS & 3 & 5.9 \\
\hline Infantile NS & 1 & 2.0 \\
\hline Childhood NS & 38 & 74.5 \\
\hline Acute nephritis & 7 & 13.7 \\
\hline Recurrent gross hematuria & 2 & 3.9 \\
\hline Total & 51 & 100.0 \\
\hline
\end{tabular}

Provisional diagnosis of the cases in the retrospective study was primarily NS $(76.6 \%)$ followed by acute nephritis $(23 \%)$ then recurrent gross hematuria (4.1\%) (Table 3).

Regarding the definitive diagnosis of the cases, SDNS was the most common diagnosis representing $23.4 \%$ of the cases (Table 4 ).

Table 4: The different definitive diagnoses of the cases

\begin{tabular}{|c|c|c|}
\hline \multirow[t]{2}{*}{ Diagnosis } & Retrospective study $(\mathrm{n}=543)$ & Percent \\
\hline & \multicolumn{2}{|l|}{ Frequency } \\
\hline Alport syndrome & 6 & 1.1 \\
\hline congenital NS Finnish type & 3 & 0.6 \\
\hline congenital NS DMS* & 5 & 0.9 \\
\hline $\mathrm{HSP}^{* *}$ & 1 & 0.2 \\
\hline IgA nephropathy & 6 & 1.1 \\
\hline IgM nephropathy & 2 & 0.4 \\
\hline Lupus nephritis & 6 & 1.1 \\
\hline $\mathrm{PSGN}^{* * *}$ & 103 & 19.0 \\
\hline SDNS**** & 127 & 23.4 \\
\hline SDNS turns into $\mathrm{FR}^{\star \star \star \star \star *}$ & 4 & 0.7 \\
\hline SDNS turns into $I \mathrm{R}^{\star \star \star \star \star \star \star}$ & 94 & 17.3 \\
\hline SRNS $S^{* \star * \star * \star *}$ & 62 & 11.4 \\
\hline SRNS turns into IR & 12 & 2.2 \\
\hline SSNS $S^{\star \star \star \star \star \star \star \star *}$ & 72 & 13.3 \\
\hline Thin basement membrane disease & 5 & 0.9 \\
\hline not yet diagnosed & 35 & 6.4 \\
\hline Total & 543 & 100.0 \\
\hline \multirow[t]{2}{*}{ Diagnosis } & Prospective study $(n=51)$ & Percent \\
\hline & \multicolumn{2}{|l|}{ Frequency } \\
\hline SSNS & 12 & 23.5 \\
\hline SRNS & 9 & 17.6 \\
\hline SDNS & 6 & 11.8 \\
\hline SDNS turns into IR & 6 & 11.8 \\
\hline PSGN & 6 & 11.8 \\
\hline IgA nephropathy & 1 & 2.0 \\
\hline Lupus nephritis & 1 & 2.0 \\
\hline Not yet diagnosed & 10 & 19.6 \\
\hline Total & 51 & 100.0 \\
\hline
\end{tabular}
the study participants showed that C3 complement was performed for 157 (28.9\%) patients, and it was consumed in $54.1 \%$ of them. C4 complement was done for $154(28.4 \%)$ patients; $13.6 \%$ of them had consumed level. Renal biopsy was performed for 128 (32.6\%) of the patients, and the most common finding was MCNS representing $27.3 \%$ of the biopsies (Table 5 ).

Table 6 demonstrates the patterns of presentations among different diagnoses in the cases of the retrospective part of the study.

Table 7 shows the different definitive diagnoses in relation to provisional diagnosis in the study participants.

\section{Prospective part of the study}

In the prospective stage, 51 children were included in the study. Data of all eligible children who were newly provisionally diagnosed with glomerular disease in pediatric nephrology clinic at the Children Hospital, Cairo University in a period of 6 months (between February 2016 and July 2016) were recruited.

The demographic characteristics of the study participants showed that the mean age was $4.5 \pm$ 2.7 years, male to female ratio was 1.3:1 (Table 1). 
Regarding the clinical features of the cases at presentation, the majority of patients $(76.5 \%)$ were presented with NS. At the end of follow-up $88.2 \%$ of them had Stage $1 \mathrm{CKD}$, while $11.8 \%$ showed complete resolution (Table 2).

\section{Table 5: Complement level and renal biopsy findings}

\begin{tabular}{|c|c|c|}
\hline Complements levels & Retrospective study $(n=543)$ & Percent \\
\hline C3 Complement level & Frequency & \\
\hline Normal & 72 & 45.9 \\
\hline Consumed & 85 & 54.1 \\
\hline Total & 157 & 100.0 \\
\hline C4 Complement level & Frequency & Percent \\
\hline Normal & 133 & 86.4 \\
\hline Consumed & 21 & 13.6 \\
\hline Total & 154 & 100.0 \\
\hline Biopsy findings & Frequency & Percent \\
\hline NS: MCNS* & 35 & 27.3 \\
\hline NS: FSGS** & 30 & 23.4 \\
\hline NS: Mesangioproliferative $\mathrm{GN}^{\star \star \star}$ & 12 & 9.4 \\
\hline NS: Membranous GN & 3 & 2.3 \\
\hline Crescentric GN & 5 & 3.9 \\
\hline Membranous GN & 1 & 0.8 \\
\hline $\mathrm{MPGN}^{\star \star \star \star}$ & 1 & 0.8 \\
\hline CNS: DMS ${ }^{\star \star \star \star \star *}$ & 5 & 3.9 \\
\hline $\mathrm{CNS}^{\star \star \star \star * \star *}$ : Finnish type & 3 & 2.3 \\
\hline Alport & 6 & 4.7 \\
\hline IgA nephropathy & 5 & 3.9 \\
\hline IgM nephropathy & 2 & 1.6 \\
\hline $\mathrm{LN}^{\star \star \star \star \star \star \star *}$ & 4 & 3.1 \\
\hline Thin basement membrane disease & 4 & 3.1 \\
\hline Others: FSGS & 6 & 4.7 \\
\hline Others: Mesangioproliferative GN & 5 & 3.9 \\
\hline Others: Thrombotic microangiopathy & 1 & 0.8 \\
\hline Total & 128 & 100.0 \\
\hline \multirow[t]{2}{*}{ C3 Complement level } & Prospective study $(\mathrm{n}=51)$ & \multirow[t]{2}{*}{ Percent } \\
\hline & Frequency & \\
\hline Normal & 10 & 66.7 \\
\hline Consumed & 5 & 33.3 \\
\hline Total & 15 & 100.0 \\
\hline C4 Complement level & Frequency & Percent \\
\hline Normal & 15 & 100.0 \\
\hline Biopsy findings & Frequency & Percent \\
\hline NS: FSGS & 4 & 33.3 \\
\hline NS: MCNS & 4 & 33.3 \\
\hline NS: Mesangioproliferative GN & 2 & 16.7 \\
\hline LN & 1 & 8.3 \\
\hline IgA nephropathy & 1 & 8.3 \\
\hline Total & 12 & 100.0 \\
\hline
\end{tabular}

Provisional diagnosis of the cases in the prospective study was primarily NS $(82.4 \%)$, followed by acute nephritis $(13.7 \%)$ and recurrent gross hematuria (3.9\%) (Table 3).

Definitive diagnoses of the cases showed that SSNS was the most common diagnosis representing $23.5 \%$ of the cases (Table 4 ).

$\mathrm{C} 3$ and $\mathrm{C} 4$ complements were performed for 15 patients $(29.4 \%)$. C3 was consumed in 5 cases $(33.3 \%)$, while C4 was normal in all 15 cases. Biopsy was performed for 12 cases $(23.5 \%)$ of the patients. The most common findings of the biopsies were MCNS and FSGS (Table 5).

Table 6 demonstrates the patterns of presentations among the different diagnoses in the study participants of the prospective part.

Table 7 shows the different definitive diagnoses in relation to the provisional diagnosis in the study participants.

\section{Discussion}

Regarding the demographic criteria (e.g., age and sex) of our study subjects, there are similar studies. For instance, in a retrospective study done by reviewing records of all admitted pediatrics under 14 years of age with INS, it was found that the mean age is $4.98 \pm 2.61$ years in the population study. In that study, male to female ratio was 2:1 [10]. In another retrospective study that included a review of 321 children seen with nephrosis/nephritis;

Table 6: Pattern of presentations in study cases

\begin{tabular}{|c|c|c|c|c|c|c|c|c|c|}
\hline \multicolumn{10}{|l|}{ Retrospective study $(\mathrm{n}=543$ ) } \\
\hline Diagnosis & $\mathrm{NS}^{*}$ & Nephritis & Gross hematuria & $\mathrm{NO} / \mathrm{NE}^{* *}$ & $\begin{array}{l}\text { Microscopic } \\
\text { hematuria }\end{array}$ & $\mathrm{ARF}^{* * *}$ & $\begin{array}{l}\text { Accidently } \\
\text { discovered } \\
\text { proteinuria }\end{array}$ & $\begin{array}{l}\text { Asymptomatic } \\
\text { persistent } \\
\text { proteinuria }\end{array}$ & Total \\
\hline Alport syndrome & 0 & 1 & 5 & 0 & 0 & 0 & 0 & 0 & 6 \\
\hline Congenital NS DMS & 3 & 0 & 0 & 2 & 0 & 0 & 0 & 0 & 5 \\
\hline$H S P^{\star \star \star \star \star \star}$ & 0 & 1 & 0 & 0 & 0 & 0 & 0 & 0 & 1 \\
\hline IgA nephropathy & 0 & 1 & 5 & 0 & 0 & 0 & 0 & 0 & 6 \\
\hline IgM nephropathy & 0 & 2 & 0 & 0 & 0 & 0 & 0 & 0 & 2 \\
\hline Lupus nephritis & 0 & 4 & 1 & 0 & 1 & 0 & 0 & 0 & 6 \\
\hline $\mathrm{PSGN}^{* \star * * \star *}$ & 1 & 64 & 38 & 0 & 0 & 0 & 0 & 0 & 103 \\
\hline SDNS $^{\star \star * \star * \star *}$ & 126 & 0 & 0 & 0 & 0 & 0 & 1 & 0 & 127 \\
\hline SDNS turns into $\mathrm{FR}^{\star \star \star \star \star \star \star \star \star \star ~}$ & 3 & 0 & 0 & 1 & 0 & 0 & 0 & 0 & 4 \\
\hline SDNS turns into $\mathrm{IR}^{\star \star \star \star \star \star \star \star \star \star ~}$ & 94 & 0 & 0 & 0 & 0 & 0 & 0 & 0 & 94 \\
\hline SRNS SR* $^{\star \star \star \star \star \star \star \star \star \star \star ~}$ & 49 & 2 & 0 & 11 & 0 & 0 & 0 & 0 & 62 \\
\hline SRNS turns into IR & 10 & 1 & 0 & 1 & 0 & 0 & 0 & 0 & 12 \\
\hline SSNS $S^{\star \star \star \star \star \star \star \star \star \star \star \star ~}$ & 70 & 0 & 0 & 2 & 0 & 0 & 0 & 0 & 72 \\
\hline Thin basement membrane disease & 0 & 4 & 1 & 0 & 0 & 0 & 0 & 0 & 5 \\
\hline Total & 369 & 89 & 57 & 19 & 4 & 3 & 1 & 1 & 543 \\
\hline Diagnosis & \multicolumn{2}{|l|}{ NS } & \multicolumn{2}{|c|}{ Prospective study $n=51$} & $\mathrm{NO} / \mathrm{NE}$ & \multicolumn{2}{|c|}{ Gross hematuria } & \multicolumn{2}{|l|}{ Total } \\
\hline IgA nephropathy & \multicolumn{2}{|l|}{0} & \multicolumn{2}{|l|}{0} & 0 & \multicolumn{2}{|l|}{1} & \multicolumn{2}{|l|}{1} \\
\hline LN & \multirow{2}{*}{\multicolumn{2}{|c|}{$\begin{array}{l}0 \\
9\end{array}$}} & \multirow{2}{*}{\multicolumn{2}{|c|}{$\begin{array}{l}0 \\
0\end{array}$}} & 1 & \multicolumn{2}{|l|}{0} & \multicolumn{2}{|l|}{1} \\
\hline Not yet diagnosed & & & & & 0 & \multicolumn{2}{|l|}{1} & \multicolumn{2}{|l|}{10} \\
\hline PSGN & \multicolumn{2}{|l|}{0} & \multicolumn{2}{|l|}{6} & 0 & \multicolumn{2}{|l|}{0} & \multicolumn{2}{|l|}{6} \\
\hline SDNS & \multicolumn{2}{|l|}{6} & \multicolumn{2}{|l|}{0} & 0 & \multirow{2}{*}{\multicolumn{2}{|c|}{$\begin{array}{l}0 \\
0\end{array}$}} & \multicolumn{2}{|l|}{6} \\
\hline SDNS turns into IR & \multicolumn{2}{|l|}{6} & \multicolumn{2}{|l|}{0} & 0 & & & \multicolumn{2}{|l|}{6} \\
\hline SRNS & 7 & & 0 & & 2 & \multicolumn{2}{|l|}{0} & 9 & \\
\hline SSNS & 11 & & 0 & & 1 & 0 & & 12 & \\
\hline Total & 39 & & 6 & & 4 & 2 & & 51 & \\
\hline
\end{tabular}


Table 7: Definitive diagnoses in relation to provisional diagnosis

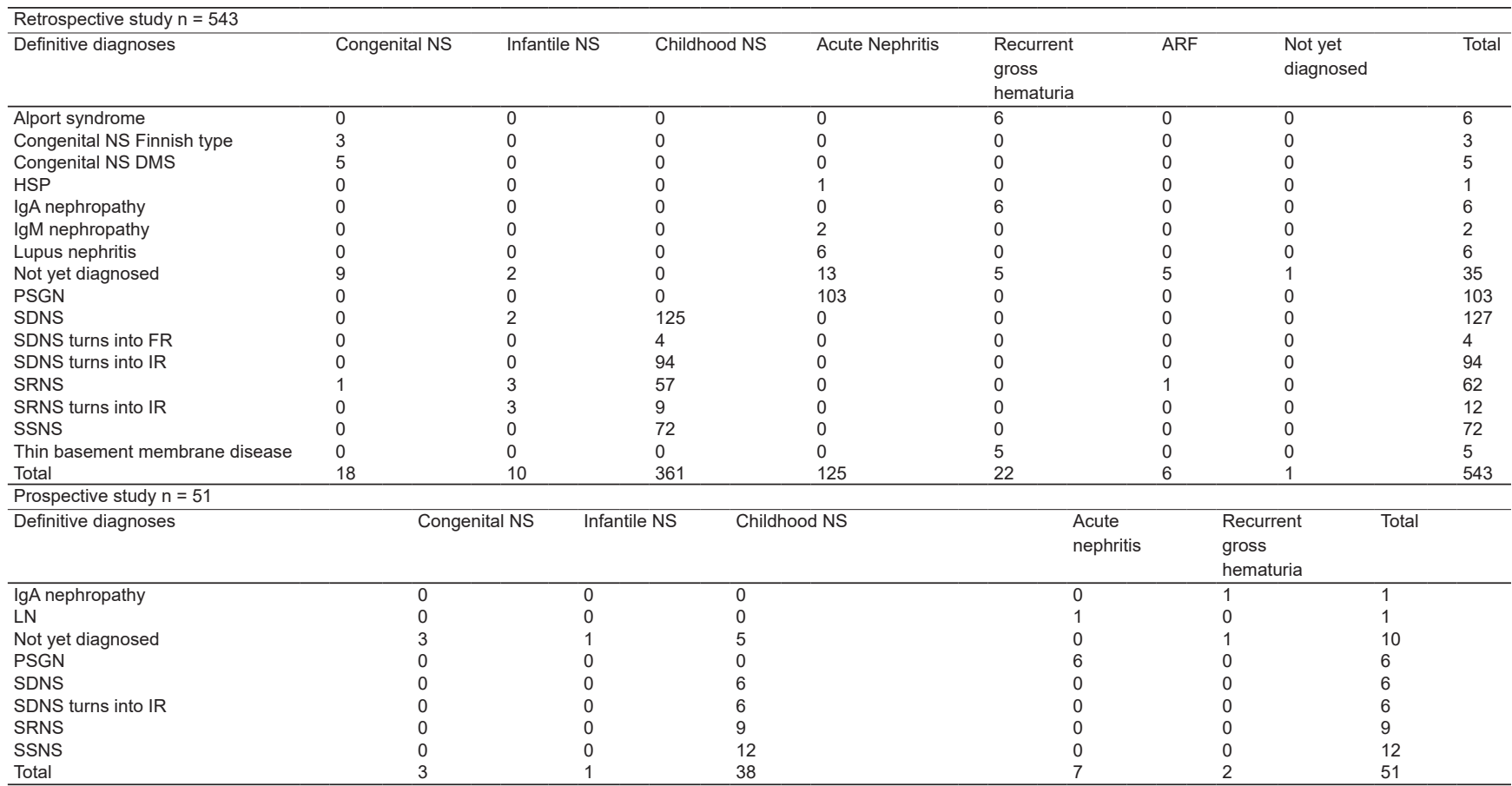

it was found that the mean age was 8.71 years (range: 2 months-16 years) [11]. The results of these studies may not be totally similar to our study due to that, in our study, the upper limit of accepted age was less than 12 years.

Regarding the male to female ratio, this study agrees with a former retrospective review in which there was a higher male percentage than females (125 males [50.4\%] and 123 females [49.6\%]) [12].

Regarding the presentations, our results agree with Abdelraheem et al. in 2010, who found that NS was the most common presentation, which was seen in $62.9 \%$ of the enrolled children. The other $37.1 \%$ children presented with nephritic syndrome and/or mixed features. In that study, the most common glomerular disease was idiopathic NS, with a pathology of minimal change disease (MCD) seen in $29.9 \%$. Post-infectious GN was seen in $24.3 \%$. The least common were Alport's syndrome, IgA nephropathy. SLE was the most common secondary glomerular disease, which accounted for $4.9 \%$ [11]. This does not totally agree with our study as LN frequency is not so high as most of them were following up in the rheumatology (not the nephrology) clinic.

Regarding the biopsies results, our study agrees with findings of a previous study done on children presented with nephritis. It was reported that in children, MCD (88\%) was the single most common cause of NS. FSGS was (5.9\%) of them [13].

Our results are very near to the findings of Shawarby et al., who found that minimal change glomerulopathy $(29.4 \%)$ was the most common result [14]. Mesanioproliferative GN was (19.8\%). FSGS was (15.5\%). Membranous glomerulopathy was in $(8.6 \%)$. IgA nephropathy was in $(6.4 \%)$. Crescentic
GN was in (3.2\%) and IgM nephropathy in (1.6\%) of the study population. This study was a retrospective one done on 233 patients.

In the study done by Arias et al., it was found that FSGS was the most frequent type of glomerulopathy $(34.8 \%)$ of the study population [15]. This study was a retrospective study. All native renal biopsies (July 1998 to December 2007), but only glomerular diseases were analyzed, and the age of the pediatric patients was $<15$ years. The difference between this study and ours may be attributed to both various races and altered environmental conditions.

Regarding the outcomes of the study groups, our result agrees with Mahmud et al. who found that CKD Stage 1 was (52\%), CKD Stage 2 was (22\%), CKD Stage 3 was (14\%), CKD Stage 4 was $(7.3 \%)$, and CKD Stage 5 was (2.9\%) of the study participants. It was an observational cohort study.

The prognosis and outcome were the most excellent with PSGN, as the present retrospective study showed that $(99.0 \%)$ of those with PSGN ended in resolution, and only (1.0\%) of them ended in the CKD Stage2 [16].

In another retrospective study of post-infectious GN, it was found that ESRD was in $14.3 \%$ (4 out of 28 cases) [17]. This difference may be due to that our present retrospective and prospective studies were done at the nephrology clinic of glomerular diseases on Monday and Thursday and not at the nephrology clinic of renal failure that was on Sunday. Hence, patients of PSGN who entered in ESKD were not included in the study.

Regarding the definitive diagnoses, our results agree with what was reported in a retrospective review 
of the children admitted with the diagnosis of new-onset idiopathic NS. It was found that the initial response to corticosteroid therapy was $66.8 \%$ of the study population [18]. Furthermore, this result agrees with Mortazavi et al. who found that a total of 124 patients $(75.2 \%)$ of the study population responded to steroids. Forty-one patients $(24.8 \%)$ of them were steroidresistant [10].

\section{Conclusion}

The most common glomerular disease in childhood is NS. Most of the cases with NS are steroid responders. Fortunately, glomerular diseases have mostly good outcomes, especially those with PSGN

\section{Limitations of the Study}

- There are some limitations to this study, common to observational studies. A large number of different observers may present inconsistencies in clinical observations. The retrospective nature of the study limited the amount of data that could be collected. Furthermore, the field of the current study was the nephrology clinics to detect patients with glomerular diseases coming for follow-up. Therefore, the study could not detect the number of deaths from the diseases; also, it is dependent on the patient's compliance, and their regularity in follow-up visits

- Another important limitation is the noncompliance of the patients. As the study location is $\mathrm{CHCU}$ which is a tertiary care hospital and many patients could miss the regular follow-up or may be non-compliant with medications due to the far distance between their residence and the hospital as actually many patients come from other governorates. This may be the cause that why CKD Stage 1 was the prognosis of some diseases which aren't known to end in CKD Stage 1.

- In addition, we do not have the policy of screening for microscopic hematuria or proteinuria. Therefore, the indications of biopsy in our study do not include persistent microhematuria (urine analyses screening) or non-nephrotic range proteinuria

Furthermore, pediatric patients who have vasculitis with renal involvement do not follow mainly in the nephrology clinic. They follow in the rheumatology clinic. Therefore, they were not mainly included in the study.

\section{Autors' Contributions}

Contributors: (1) Hoda Atef Abdelsattar Ibrahim (2) Aya Ahmed Amin , (3) Ahmed S. Zeid , (4) Samar Sabry , (5) Hesham Safouh. Contributors 1, 5: conceived the study. Contributors 1, 4, and 5: designed study. Contributors 1, 3, 4, 5: defined intellectual content. Contributors 1, 3, 4, and 5: involved in literature search. Contributors 1: acquired data. Contributors 1, 2 : analyzed data. Contributors 1, 2: involved in statistical analysis. Contributors 1, 2, 5: prepared the manuscript. Contributors: 1, 2, 5: contributed to editing of the manuscript. Contributors 1, 2, 5: reviewed the manuscript.

\section{References}

1. Hebert LA, Parikh S, Prosek J, Nadasdy T, Rovin BH Differential diagnosis of glomerular disease: A systematic and inclusive approach. Am J Nephrol. 2013;38(3):253-66. https:// doi.org/10.1159/000354390

PMid:24052039

2. Thakkar K, Poyekar S. Pattern of pediatric renal diseases in a rural tertiary care hospital. Int J Contemp Pediatr. 2020;7:2152-6.

3. Garyal, Kafle RK. Hisopathological spectrum of glomerular disease in Nepal: A seven-year retrospective study. Nepal Med Coll J. 2008;10(2):126-8.

PMid:18828437

4. Khakurel S, Agrawal RK, Hada R. Pattern of glomerular disease in Nepal: A single-center experience. Saudi J Kidney Dis Transpl. 2015;26(4):833-8. https://doi.org/10.4103/1319-2442.160249 PMid:26178570

5. Hurtado A, Escudero E, Stromquist CS, Urcia J, Hurtado ME, Gretch D, et al. Distinct patterns of glomerular disease in Lima, Peru. Clin Nephrol. 2000;53(5):325-32.

PMid:11305805

6. AlYousef A, AISahow A, AlHelal B, Alqallaf A, Abdallah E, Abdellatif $\mathrm{M}$, et al. Glomerulonephritis histopathological pattern change. BMC Nephrol. 2020;21(1):186. https://doi.org/10.1186/ s12882-020-01836-3.

PMid:32423387

7. Makris K, Spanou L. Acute kidney injury: Definition, pathophysiology and clinical phenotypes. Clin Biochem Rev. 2016;37(2):85-98.

PMid:28303073

8. Chapter 1: Definition and classification of CKD. Kidney Int Suppl. 2013;3(1):19-62. https://doi.org/10.1038/kisup.2012.64 PMid:25018975

9. Inker LA, Astor BC, Fox CH, Isakova T, Lash JP, Peralta CA, et al. KDOQI US commentary on the 2012 KDIGO clinical practice guideline for the evaluation and management of CKD. Am J Kidney Dis. 2014;63(5):713-35. https://doi.org/10.1053/j. ajkd.2014.01.416 PMid:24647050

10. Mortazavi F, Khiavi YS. Steroid response pattern and outcome of pediatric idiopathic nephrotic syndrome: A singlecenter experience in Northwest Iran. Ther Clin Risk Manag. 2011;7:167-71. https://doi.org/10.2147/TCRM.S19751 PMid:21691587 
11. Abdelraheem MB, Ali EM, Mohamed RM, Hassan EG, Abdalla OA, Mekki SO, et al. Pattern of glomerular diseases in Sudanese children: A clinico-pathological study. Saudi J Kidney Dis Transpl. 2010;21(4):778-83.

\section{PMid:20587895}

12. Asif N, Mukhtar KN, Adnan F. Spectrum of glomerular diseases: An 11 year retrospective review in a tertiary care hospital in Pakistan. JUMDC. 2015;6:54-8.

13. Clement WD, Viswanath MV, Mahesh E, Rashmi K, Radhika K. Pattern of glomerular disease in patients with nephrotic syndrome-a single Centre South Indian study. Ann Int Med Dent Res. 2015;1(3):281-8.

14. Shawarby M, Al Tamimi D, Al Mueilo S, Saeed I, Hwiesh A, Al-Muhanna $F$, et al. A clinico pathologic study of glomerular disease: Experience of the king Fahd hospital of the University, Eastern Province, Saudi Arabia. Hong Kong J Nephrol. 2010;12:20-30

15. Arias, Luis Fernando et al. Glomerular diseases in a Hispanic population: Review of a regional renal biopsy database. Sao Paulo Med J. 2009;127(3):140-4. https://doi.org/10.1590/ s1516-31802009000300006

PMid:19820874

16. Mahmud HM, Kumar D, Irum H, Ali SF. Glomerular diseases outcome at one year in a tertiary care Centre. Pak J Med Sci. 2015;31(2):462-6. https://doi.org/10.12669/pjms.312.6779 PMid:26101512

17. Srisawat N, Aroonpoonsub L, Lewsuwan S, Kanjanabuch T, Avihingsanon Y, Praditpornsilpa K, et al. The clinicopathology and outcome of post-infectious glomerulonephritis: Experience in 36 adults. J Med Assoc Thai. 2006;89(2):S157-62

PMid:17044468

18. Nickavar A, Harahdashti AL. Trends in steroid response among children with idiopathic nephrotic syndrome. Iran J Kidney Dis. 2014;8(5):389-93.

PMid:25194406 